\title{
Análise multitemporal do uso e cobertura do solo na APA rio Uberaba sob o enfoque da Ecologia de Paisagens
}

\section{Multi-temporal analysis of land use and cover in the APA Uberaba River under the focus of Landscape Ecology}

\author{
Vinícius Silva Rodrigues ${ }^{1}$; Alex Garcez Utsumi² \\ ${ }^{1}$ Aluno do Programa de Mestrado Acadêmico em Ciência e Tecnologia Ambiental, Universidade Federal do Triângulo \\ Mineiro, Uberaba, Minas Gerais, Brasil. E-mail: vinicius.s.r@hotmail.com \\ ${ }^{2}$ Professor do Curso de Graduação de Engenharia Ambiental, Universidade Federal do Triângulo Mineiro, Uberaba, \\ Minas Gerais, Brasil. E-mail: alex.utsumi@uftm.edu.br
}

\begin{abstract}
RESUMO: A ecologia de paisagens é uma ciência que busca compreender a heterogeneidade espacial dos elementos que compõem uma paisagem, relacionando essa heterogeneidade com a biodiversidade e a ação do homem. O presente trabalho objetivou realizar a análise multitemporal do uso e cobertura do solo da APA do rio Uberaba, sob o enfoque da ecologia de paisagens. Para isso, realizou-se a classificação supervisionada de imagens Landsat 5,7 e 8 para os anos de 1984, 1994, 2004 e 2014, por meio do software Qgis 2.8.2. O software Fragstats 4.2 foi utilizado para o cálculo das seguintes métricas de paisagens: Área total, Número de manchas, Comprimento total de bordas, Índice de forma médio, Distância média do vizinho mais próximo e Índice de Proximidade média ponderado pela área. Os resultados mostraram que entre 1984 e 1994 houve melhoria das condições de configuração espacial e composição para a cobertura florestal, chegando a ocupar $32 \%$ da paisagem da APA. Após esse período, nota-se o avanço das atividades agropecuárias, explicado pela redução de $30,3 \%$ do número de fragmentos florestais juntamente com a redução de $16,2 \%$ da área total dessa classe. Além disso, fragmentos florestais maiores ficaram mais isolados, e com formatos mais irregulares, o que contribuiu para o aumento do efeito de borda. As métricas de paisagens foram úteis no entendimento da dinâmica da estrutura da APA, podendo auxiliar em futuras políticas públicas de conservação.
\end{abstract}

Palavras-chave: Fragmentos florestais; Unidades de Conservação; Análise espacial; Sistema de Informação Geográfica.

ABSTRACT: Landscape ecology is a science that endeavors to understand spatial heterogeneity of landscape elements, relating with biodiversity and human action. This study aimed to accomplish multitemporal analysis of land cover at Uberaba River Environmental Protection Area (APA), under the focus of landscape ecology, for the years 1894, 1994, 2004 and 2014. For this, the supervised classification of Landsat images 5,7 and 8 was carried out for the years of 1984, 1994, 2004 and 2014, through software Qgis 2.8.2. Fragstats 4.2 software was used to calculate the following landscape metrics: Total area, Number of patches, Total edge length, Mean shape index, Mean distance of the nearest neighbor and area-weighted average Proximity Index. From 1984 to 1994 it is clear an improvement of spatial configuration and composition of forest cover, reaching $32 \%$ of the APA landscape. After this period, advance of farming activities is notable, explained by the reduction of $30.3 \%$ in the number of forest patches and $16.2 \%$ of total area. In addition, larger forest fragments became more isolated, with more irregular shapes, which contributed to the increase of the edge effect. The landscape metrics were useful in understanding the dynamics of the APA structure, and may help in future public conservation policies

Keywords: Forest fragments; Conservation Units; Spatial analysis; Geographic Information System. 
INTRODUÇÃO

Alguns impasses ambientais, como mudanças no clima local, isolamento de habitats, alteração do regime hídrico bem como incremento da erosão dos solos são consequências da progressiva intervenção antrópica sobre a vegetação nativa de uma paisagem (SAUNDERS et al., 1991). Essas intervenções vêm sendo estudadas sob várias perspectivas, uma delas sob o ponto de vista da Ecologia de Paisagens, a qual tem como principal enfoque a compreensão da influência da heterogeneidade espacial sobre os processos ecológicos em uma paisagem (TURNER, 2005).

Um dos pré-requisitos para a aplicação da Ecologia de Paisagens é a capacidade de quantificar sua estrutura e para isso são bastante utilizados os índices ou métricas de paisagem (MCGARIGAL; MARKS, 1994). As técnicas de geoprocessamento, como o Sensoriamento Remoto e Sistemas de Informações Geográficas, surgem como ferramentas de aquisição, manipulação e representação de dados espaciais de uma paisagem. Isso permite a quantificação dos elementos da paisagem a partir de um mapa de uso e cobertura do solo (FARINA, 2006). O emprego dessas técnicas aliadas à Ecologia de Paisagens, possibilitou a produção de uma vasta literatura sobre procedimentos e métricas de quantificação da estrutura da paisagem. Para enfatizar essa perspectiva, um levantamento feito por Uuemaa (2013) mostrou que no período de 2000 a 2010 houve um aumento no número de pesquisas voltadas para a Ecologia de Paisagens em suas diversas categorias de aplicação mostrando-se promissora para estudos ambientais.

$\mathrm{Na}$ paisagem da bacia do rio Uberaba, em especial, existem estudos que evidenciam alguns problemas ambientais decorrentes do avanço agropecuário na região, como perda de fertilidade do solo em regiões de conflito ambiental de uso da terra (VALERA et al., 2016), risco de erosão nessas áreas de conflito ambiental (VALLE JUNIOR, 2008), aumento do grau de degradação ambiental na paisagem (CÂNDIDO et al., 2010) e baixa qualidade da água em pequenas bacias antrópicas (VALERA et al., 2019). Com relação a APA do rio Uberaba, Abdala (2005) propôs um zoneamento ambiental com o intuito de assegurar a conservação dos recursos hídricos da região. Apesar desses trabalhos trazerem informações importantes para a gestão da bacia e de parte dela, não há estudos que abordam a Ecologia de Paisagens na APA. Assim, o presente estudo buscou trazer uma contribuição para uma futura complementação do plano de manejo da APA e para estudos dessa temática com informações adicionais, levando em consideração a grande importância da APA para o abastecimento de água do município.

Nesse contexto, o presente estudo teve como objetivo principal realizar uma análise multitemporal do uso e cobertura do solo na Área de Proteção Ambiental do rio Uberaba utilizando técnicas de geoprocessamento e métricas de paisagens, visando compreender suas mudanças para auxiliar na qualidade ambiental da região.

\section{MATERIAIS E MÉTODOS}

\section{Localização da área de estudo}

A área de estudo está situada no município de Uberaba entre as coordenadas geográficas $19^{\circ} 30^{\prime} 0^{\prime \prime}-19^{\circ} 46^{\prime} 0^{\prime \prime}$ sul e $47^{\circ} 56^{\prime} 0^{\prime \prime}-47^{\circ} 40^{\prime} 0^{\prime \prime}$ oeste (Figura 1). A Área de Proteção Ambiental do rio Uberaba engloba aproximadamente 53.500 há, incluindo $8 \%$ de 
área urbana, situada a montante do ponto de captação de água na bacia do rio Uberaba. A nascente do rio Uberaba está em uma região de planalto a 1.012 metros de altitude, próximo ao trevo de Ponte alta na BR 262, e percorre $140 \mathrm{~km}$ até sua foz no rio Grande. O rio Uberaba possui como principais afluentes os córregos dos Pintos, da Saudade, Borá, Alegria e Lanoso.

$\mathrm{Na}$ APA o solo é coberto, principalmente, por mata, cerrado, pastagem, cultura inicial, cultura avançada e campos sujos. Nessa região há predominância de pastagens e áreas agricultáveis as quais perfazem, em sua maioria, culturas de café, soja e cana-deaçúcar (UBERABA, 2012). A vegetação presente na APA do rio Uberaba é composta de diferentes fitofisionomias de Cerrado, sendo Cerradão, Veredas, Campos sujos, Matas ciliares e de topo de encostas (ABDALA, 2005). Já o clima local é caracterizado por temperaturas médias anuais de $20^{\circ}$ a $22^{\circ}$ e, segundo a classificação climática de Köppen, o município de Uberaba apresenta chuvas no verão e seca no inverno (ABDALA, 2005).

Figura 1. Localização da APA do rio Uberaba

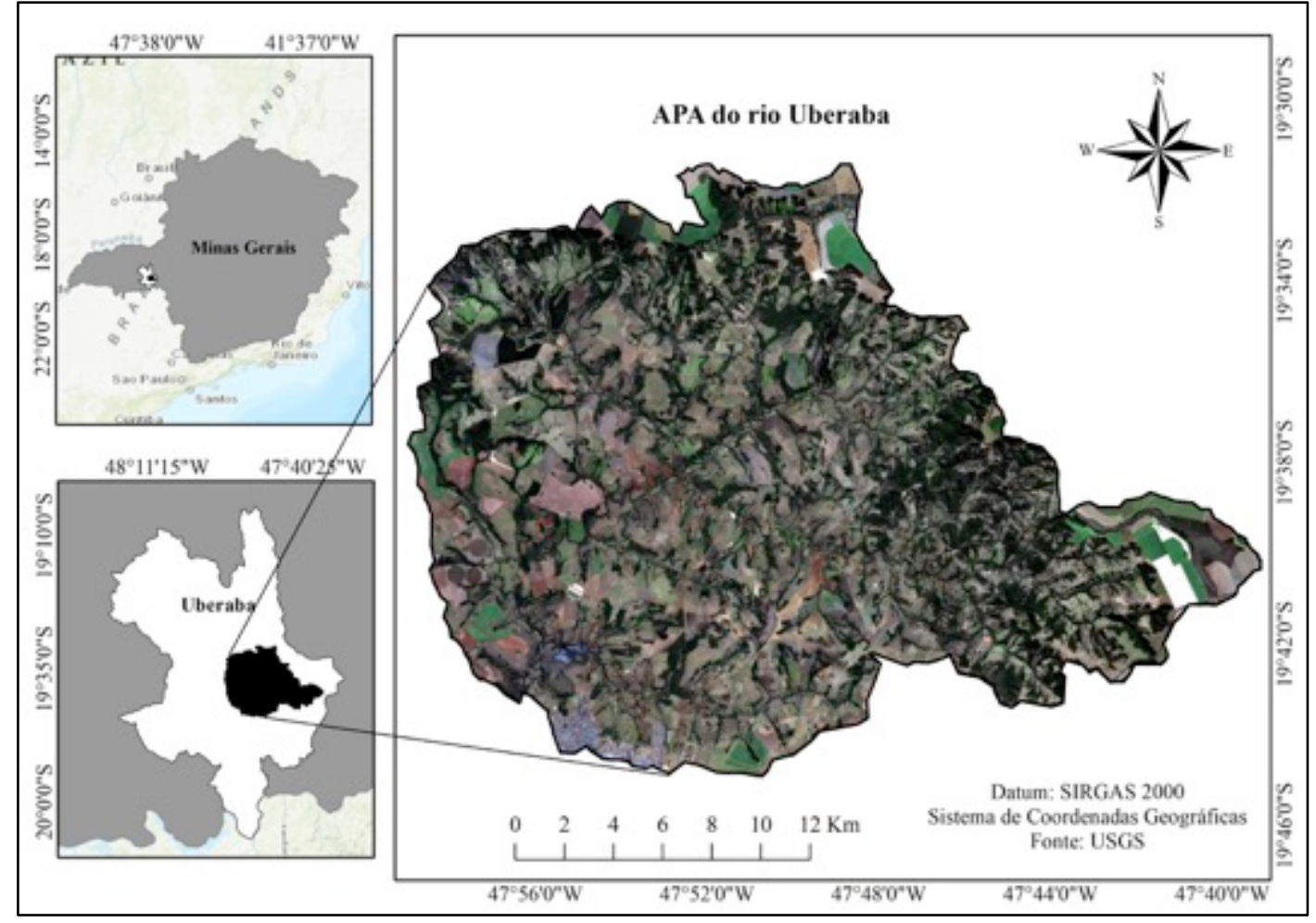

O estudo foi realizado nas seguintes etapas: aquisição e pré-processamento das imagens, classificação das imagens e cálculo das métricas de paisagem. Os softwares utilizados foram $\circ$ QGis 2.8.2 e o Fragstats 4.2, sendo o primeiro utilizado para manipulação dos dados georreferenciados e para a diagramação dos mapas e o segundo para o cálculo das métricas de paisagens.

Foram adquiridas imagens orbitais Landsat mediante o sítio eletrônico do Serviço Geológico Americano (USGS), as quais já se encontram georreferenciadas na plataforma. As seguintes datas de captura foram selecionadas: 21/06/1984 (TM/Landsat 5); 02/07/1994 (TM/Landsat 5); 28/06/2004 (ETM/Landsat 7) e 09/07/2014 (OLI/Landsat 8). Em seguida, fez-se reprojeção das imagens para o sistema de coordenadas SIRGAS 2000, projeção UTM e zona 23S. A correção atmosférica foi realizada através do 
complemento Semi-Automatic Classification Plugin (SCP) do Qgis 2.8.2, aplicando a técnica DOS (Dark Object Subtraction). A correção atmosférica visa atenuar os principais efeitos atmosféricos na radiância refletida pela superfície terrestre, a qual é detectada pelo sensor (WEISS et al., 2015). Logo após, criou-se composições falsas cores RGB 543 para as imagens do Landsat 5 e 7 e RGB 654 para a imagem do Landsat 8, visando obter o melhor contraste entre as classes.

A classificação das imagens Landsat se deu através do complemento SCP, presente no Qgis 2.8.2, de forma supervisionada utilizando o algoritmo MAXVER (máxima verossimilhança). Esse algoritmo identifica áreas homogêneas de acordo com a informação espectral isolada de cada pixel e faz uma ponderação das distâncias entre médias dos níveis digitais das classes por meio de parâmetros estatísticos (LUCAS, 2011). A classificação supervisionada consiste no fornecimento, pelo usuário, de áreas de treinamento ou amostras dos padrões na imagem que devem ser reconhecidas (PARANHOS FILHO, 2008). Nesse estudo foram selecionadas 10 amostras representativas de cada classe, as quais foram gravadas em formato shapefile. A partir dessa etapa foram obtidos os mapas temáticos de uso e ocupação do solo da APA para cada data com as seguintes classes: agricultura/pasto; solo exposto e mata.

Os índices ou métricas de paisagem podem ser mensurados em três níveis de escala, sendo a nível de fragmento individual, a nível de classe e a nível de paisagem (VOLOTÃO, 1998). O presente estudo quantificou a estrutura da paisagem a nível de classe por meio das métricas apresentadas na Tabela 1. A esse nível, tais métricas possuem os seguintes significados segundo Mcgarigal e Marks (1994):

Tabela 1. Métricas de Paisagem e suas equações

\begin{tabular}{|c|c|c|}
\hline Métrica & Sigla & Equação \\
\hline Área total da classe (ha) & CA & $C A=\sum_{j=1} a_{i j}$ \\
\hline Número de manchas & NP & $\mathrm{NP}=\sum \mathrm{n}_{\mathrm{i}}$ \\
\hline Comprimento total de borda de cada classe $(\mathrm{m})$ & TE & $\mathrm{TE}=\sum_{\mathrm{i}=1} \mathrm{e}_{\mathrm{i}}$ \\
\hline Índice de forma médio (adimensional) & MSI & MSI $=\frac{\sum_{\mathrm{i}=1}^{\mathrm{n}}\left(\frac{0,25 \mathrm{p}_{\mathrm{ij}}}{\sqrt{\mathrm{a}_{\mathrm{ij}}}}\right)}{\mathrm{n}_{\mathrm{i}}}$ \\
\hline Distância do vizinho mais próximo (m) & MNN & $\mathrm{MNN}=\frac{\sum_{\mathrm{j}=1}^{\mathrm{n}} \mathrm{h}_{\mathrm{ij}}}{\mathrm{n}_{\mathrm{i}}}$ \\
\hline $\begin{array}{c}\text { Índice de proximidade média ponderado pela } \\
\text { área (adimensional) }\end{array}$ & PROX_AM & $\operatorname{PROX}=\frac{\sum_{\mathrm{j}=1}^{\mathrm{n}} \sum_{\mathrm{s}=1}^{\mathrm{n}} \frac{\mathrm{a}_{\mathrm{ijs}}}{\mathrm{h}_{\mathrm{ijs}}^{2}}}{\mathrm{n}_{\mathrm{i}}}$ \\
\hline \multicolumn{3}{|c|}{$\begin{array}{l}\mathrm{a}_{\mathrm{ij}}=\text { área do fragmento i da classe } \mathrm{j} ; \mathrm{n}_{\mathrm{ij}}=\mathrm{i} \text {-ésima mancha de determinada classe; } \mathrm{e}_{\mathrm{i}}=\text { borda ou perímetro } \\
\text { do i-ésimo fragmento; } \mathrm{p}_{\mathrm{ij}}=\text { perímetro do fragmento } \mathrm{ij} ; \mathrm{h}_{\mathrm{ij}}=\text { distância mínima do fragmento ij ao vizinho mais } \\
\text { próximo da mesma classe; } \mathrm{a}_{\mathrm{ijs}}=\text { área do fragmento ijs dentro de uma vizinhança específica do fragmento ij; } \\
\mathrm{h}_{\mathrm{ijs}}=\text { distância entre a manchas ijs baseado na distância borda-a-borda entre fragmentos. } \\
\text { Fonte: Adaptado de Mcgarigal e Marks, } 1994 \text {. }\end{array}$} \\
\hline
\end{tabular}


CA: Somatória das áreas de todos as manchas de uma determinada classe; NP: Número total de manchas de determinada classe; TE: Medida absoluta dos perímetros de todas as manchas de uma classe; MSI: Índice adimensional que representa o grau de complexidade das manchas comparado a um formato circular padrão; MNN: Somatório das distâncias borda-a-borda mínimas ao vizinho mais próximo da mesma classe; PROX_AM: Métrica adimensional calculado pela soma das áreas das manchas de uma classe dividido pela distância borda-a-borda mais próxima entre os fragmentos dentro de um raio de busca especificado. Nesse caso, a ponderação pela área representa a relação entre a área total de uma classe com a área total da paisagem. O índice PROX_AM foi calculado dentro de um raio de busca de 500 m, com base em Galetti (2013).

\section{RESULTADOS E DISCUSSÃO}

Com base no mapeamento temporal (Figura 2) e quantificação da estrutura da paisagem da APA do rio Uberaba entre 1984 e 2014, foi possível constatar a influência antrópica na configuração e composição da paisagem. No geral, por meio de observação visual da Figura 2, é possível perceber as áreas agropecuárias como sendo a matriz da paisagem, assim como uma grande abrangência da classe Solo exposto no ano de 2014.

Figura 2. Evolução do uso e cobertura do solo na APA do rio Uberaba
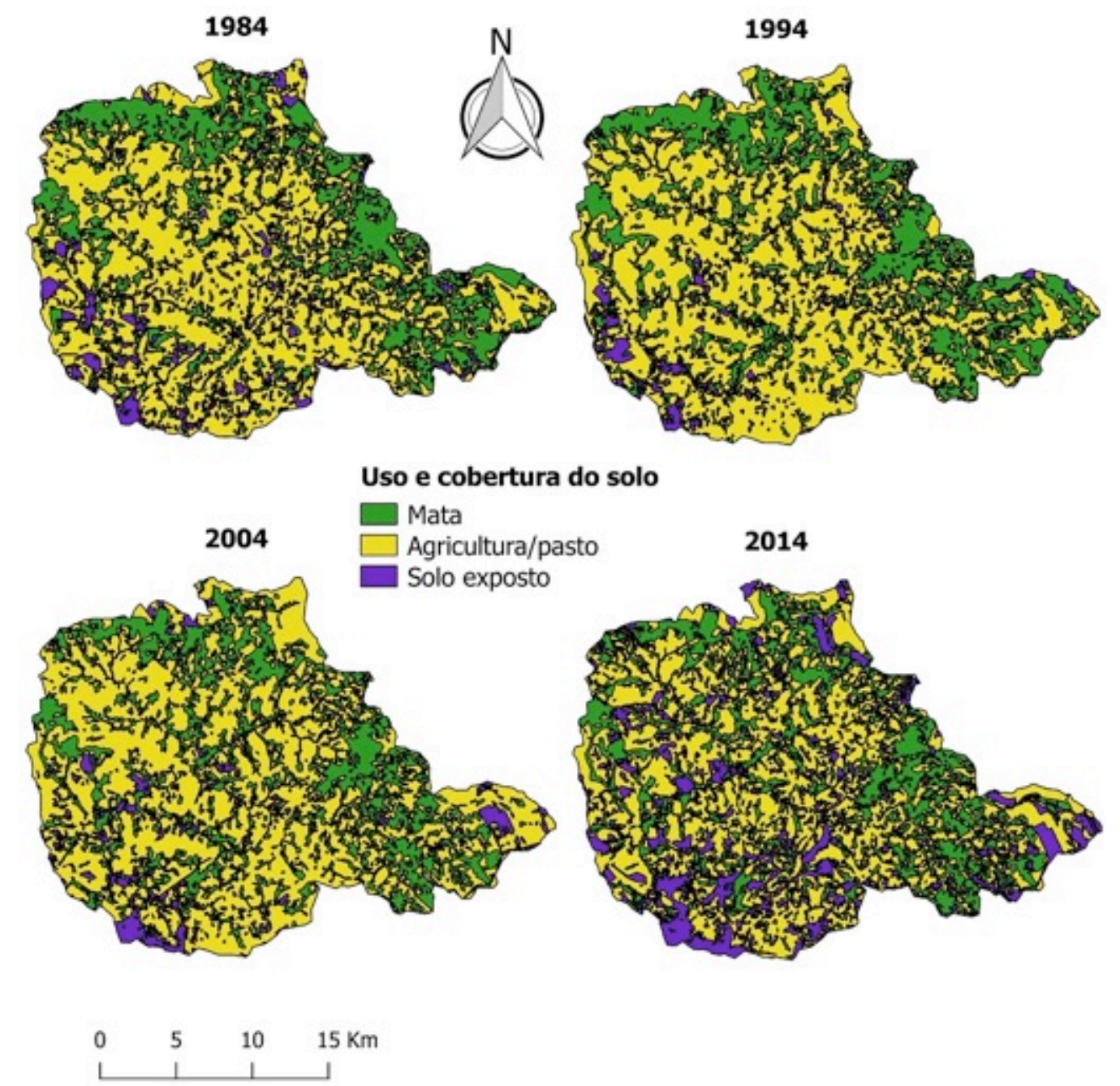

\begin{tabular}{|l|l|l|l|l|l|l} 
Rev. Bras. Cien., Tec. e Inov. & Uberaba, MG & v. 4 & n. 1 & p. $83-94$ & jan./jun./2019 & ISSN 2359-4748 \\
\hline
\end{tabular} 


\section{Uso e Cobertura do Solo}

A classificação do uso e cobertura do solo mostrou que a classe agricultura/pasto teve maior abrangência em 2004 com cerca de 65\% da APA (33.871 ha) e menor em 2014 com cerca de $55 \%$ da APA (28.988 ha). Resultado semelhante é observado no estudo de Rusca et al. (2017), a qual mostra que a paisagem no entorno da EEA do município de Avaré-SP, apresenta cerca de $68,7 \%$ de áreas agropecuárias. Concomitantemente ao decréscimo da cobertura da classe Agricultura/pasto nesse período, houve um aumento substancial da cobertura de solo exposto (Figura 3a). Esse incremento de solo exposto, a qual corresponde, em sua maioria, em culturas no período de pousio, pode estar relacionado com os avanços da monocultura de cana-de-açúcar na região. De fato, Pereira et al. (2015) constatou que houve uma expansão significativa de áreas com o cultivo de cana-de-ácúcar na região da APA, no período de 2001 a 2009 , intervalo similar ao aqui analisado.

Figura 3. Evolução das métricas de paisagem na APA do rio Uberaba

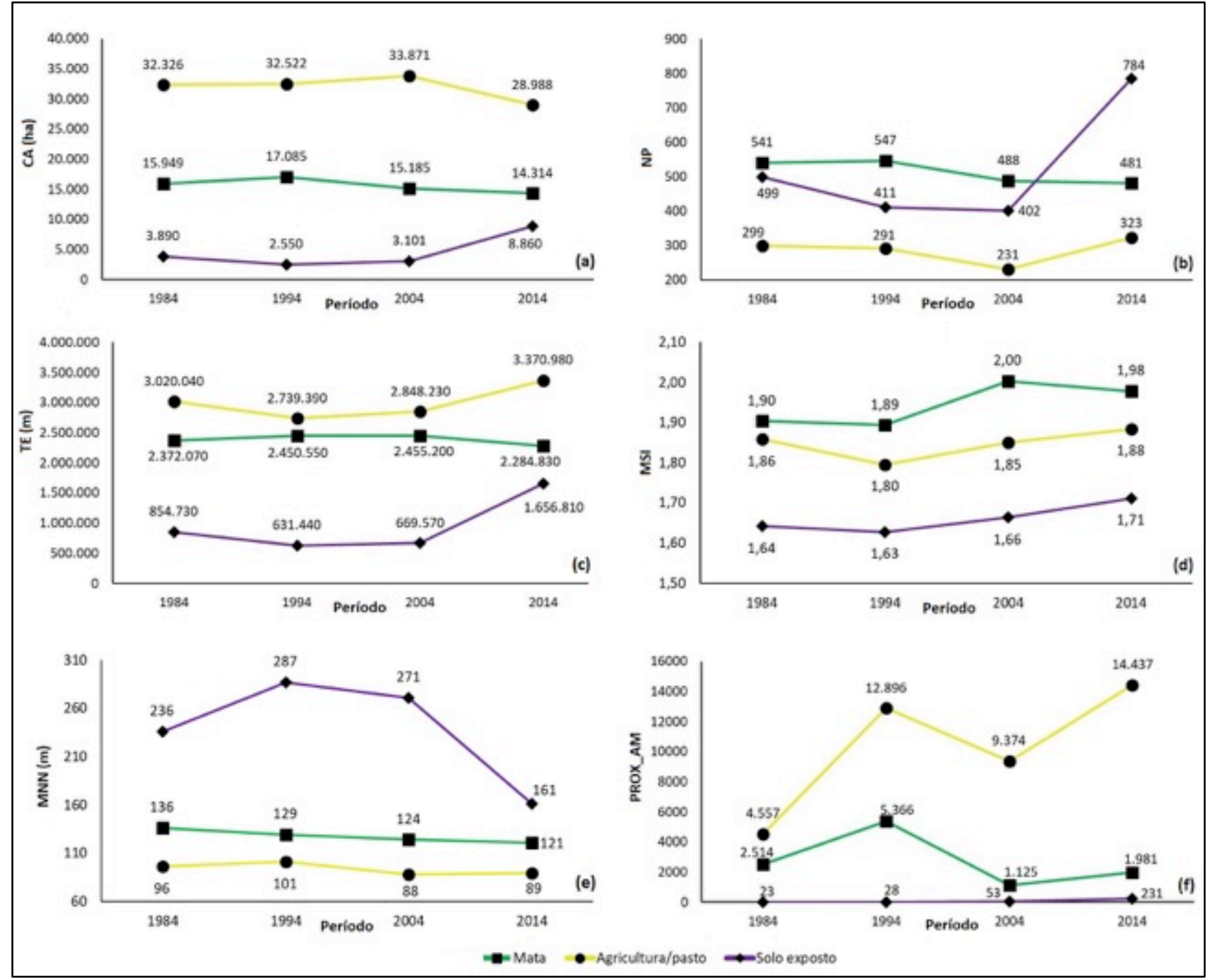

Nas áreas próximas à nascente do rio Uberaba, situada na APA, foi constatada essa substituição de vegetação nativa por da cana-de-açúcar (CÂNDIDO et al., 2010), 
caracterizado aqui pela expansão de solo exposto na região sudeste da APA. Com o avanço agropecuário, percebe-se um decréscimo da área coberta por vegetação nativa que chegou, em 2014, a um valor crítico de $27,4 \%$ da área total (14.314 ha). Regiões com elevada diversidade biológica, como a Amazônia, necessitam de $60 \%$ a $70 \%$ de habitat original para conservação dos processos ecológicos (OLIVEIRA FILHO; METZGER, 2006). Em paisagens fortemente antropizadas, como a APA do rio Uberaba, estudos apontam que uma manutenção de no mínimo $30 \%$ de mata nativa é necessário para conciliar o uso econômico e a conservação biológica (METZGER, 2010).

A manutenção da vegetação nativa, sobretudo das matas ripárias, reflete na qualidade dos recursos naturais. Valera et al. (2019), examinando três sub-bacias da APA do rio Uberaba, constataram uma fraca qualidade da água (IQA $<36 \%$ ) em função da faixa ciliar atual e do impacto do cultivo de cana-de-açúcar. O mesmo estudo indicou que seria necessária uma faixa mínima de $45 \mathrm{~m}$ de mata ripária com aumento significativo de floresta nativa para possibilitar evolução na qualidade hídrica local.

\section{Métricas de Paisagem}

A mudança do número de manchas de uma classe deve ser analisada juntamente com sua área total. Assim, a diminuição do NP e aumento de área da classe (CA) pode indicar a união de fragmentos, porém se NP e CA diminuem no mesmo período, indica a extinção de fragmentos da paisagem (CABACINHA, 2010). No caso da vegetação nativa, percebe-se, a partir de 1994, que o número de fragmentos diminui, bem como sua área total (Figura $3 a$ e $3 b$ ), sugerindo que alguns fragmentos florestais foram extintos. No período anterior, até 1994, houve um pequeno acréscimo de manchas dessa classe, passando de 541 para 547 fragmentos (Figura 3b), ao passo que a área total da classe aumenta, indicando uma possível regeneração de fragmentos florestais. Oliveira et al. (2017), analisando a mudança da estrutura da paisagem natural da porção oeste do Quadrilátero Ferrífero em Minas Gerais, também observou uma regeneração florestal caracterizada pelo aumento da métrica $\mathrm{CA}$ e manutenção do número de fragmentos florestais. Já os resultados de Barbalho (2015), em seu estudo temporal da cobertura vegetal da microrregião de Ceres nos anos de 1975, 1985 e 2012, mostraram tanto extinção de fragmentos florestais (de 1975 a 1985), caracterizada pela diminuição de CA e NP, quando o aumento do grau de fragmentação dessa classe (de 1985 a 2012), indicado pelo incremento da métrica NP e diminuição de CA.

Sobre as demais classes, destaca-se o aumento do número de manchas (de 231 para 323 manchas) acompanhado do decréscimo da área total da classe Agricultura/pasto no intervalo de 2004 a 2014. Associando esse resultado ao aumento significativo de NP e CA da classe Solo exposto, bem como o regresso dessas métricas da classe Mata (Figura 3a e 3b), pode-se inferir um aumento de área agrícola (culturas em pousio) e/ou urbana, já que estas foram classificadas como Solo exposto. Massoli Junior (2016) também verificou um aumento expressivo de Solo exposto entre 1990 e 2014 na microbacia Sepotubinha em Nova Marilândia - MT, passando de 5,15\% em 1990 para 25,03\% em 2014. O aumento de Solo exposto na APA do rio Uberaba pode estar relacionado a degradação de pastagens devido ao manejo inadequado dos mesmos, o que leva a processos erosivos prejudiciais aos ecossistemas. Valle Junior et al. (2010), por meio da equação universal da perda de solo mapeou as perdas de solo da bacia do rio Uberaba, onde boa parte da porção da APA se encontra com perdas acima do limite tolerável. 
Geralmente, o aumento da extensão das bordas (TE) é diretamente proporcional ao aumento do número de manchas (LOURENÇO, 2009). Essa proporcionalidade é constada para a classe Mata de 1984 a 1994 indicando uma regeneração florestal no período. De 1994 a 2004 o fator forma passa a explicar o aumento da métrica TE, uma vez que o número de fragmentos diminui ao passo que a métrica de forma (MSI) aumenta de 1,89 para 2,00, o que tornou os fragmentos mais irregulares e, portanto, com maiores extensões de borda. $O$ índice de forma médio possui valor mínimo de 1 e indica o quão próximo o formato de uma mancha está de uma circunferência a medida que o índice se aproxima do valor mínimo (FARINA, 2006). Manchas florestais com formatos mais complexos tendem a apresentar efeito de borda mais acentuado, principalmente fragmentos menores, devido à maior interação com a matriz da paisagem (VIDOLIN, 2011).

O aumento do efeito de borda ao longo do tempo causa perda de qualidade dos habitats florestais, uma vez que diminuem suas áreas interiores. Isso leva ao desenvolvimento espécies generalistas que, por competição ou predação, tendem a suprimir espécies habitadas em núcleos de fragmentos (METZGER, 1999; VALENTE, 2001). O aumento do índice de forma de fragmentos florestais também foi constatado no estudo de Pirovani (2015) passando de 1,83 em 1970 para 2,07 em 2007. O autor argumenta que em termos de conservação de espécies de interior fragmentos mais irregulares, porém maiores possuem maior vantagem sobre fragmentos circulares com menor área, pois estes oferecerem maior efeito de borda.

$\mathrm{Na}$ análise do isolamento das classes destaca-se um decréscimo de cerca de 11,0\% na distância média entre vizinhos mais próximos (MNN) dos fragmentos florestais no intervalo de 1984 a 2014 (Figura 3e). Entretanto, isso não significa necessariamente uma melhora na paisagem, como relata Massoli Junior (2016), pois pode ser consequência do recorte de fragmentos maiores, criando fragmentos menores e mais próximos. O mesmo autor, em seu estudo, mostra uma redução do isolamento médio dos fragmentos florestais de 275,44 m em 1990, para 95,63 m em 2014.

Ao analisar o índice de proximidade média ponderado pela área (PROX_AM), verificou-se que, de maneira geral, os fragmentos florestais de tamanhos maiores se tornaram mais isolados passando de 2.514 em 1984 para 1.981 em 2014 (Figura 3f). Vale ressaltar que dentro desse intervalo houve uma melhora no período de 1984 a 1994 chegando ao valor de 5.366 e um grau de isolamento máximo em 2004. O aumento do grau de isolamento de fragmentos maiores afeta a dispersão e movimentação de certas espécies, levando a uma biodiversidade pobre no contexto da paisagem (RUDOLPHO et al., 2013). Nesse sentido, os trampolins ecológicos (Stepping stones) ou pontos de ligação (pequenos habitats espalhados na matriz) podem exercer papel crucial na manutenção de espécies, pois amenizam o isolamento de grandes fragmentos facilitando o fluxo gênico entre os mesmos (SAURA, 2014).

Analisando as demais classes nota-se valores menores valores de MNN para a classe Agricultura/pasto ao longo dos anos, remetendo a um menor isolamento da mesma. Em 1994 a métrica MNN chega a um valor máximo de 101 metros, o que é baixo em relação às outras classes. Já nos anos de 2004 e 2014 essa métrica diminui ainda mais chegando a 88 e 89 metros respectivamente (Figura 3e). Fernandes et al. (2017), analisando a paisagem da bacia do rio Piauitinga, mostrou que as áreas de pastagem possuem menor isolamento em relação as outras classes, com valor de MNN de 24,5 
metros. Por outro lado, o estudo mostrou que as áreas de monocultura e Solo exposto possuíam valores elevados de MNN, com 112,0 e 86,7 metros respectivamente.

As manchas maiores da classe Agricultura/pasto também se tornaram mais próximas em um contexto geral, chegando a um valor máximo em 2014 (Figura 3f). Em detrimento da expansão agrícola, é possível observar uma maior proximidade entre as manchas de Solo exposto a partir de 1994, tornando mais evidente entre 2004 a 2014, período em que o número de manchas aumentou de modo acentuado. Esses resultados não se mostram satisfatórios quando considerados estudos como o de Shaker et al. (2010), que mostrou uma correlação positiva entre níveis médios de nitrato em águas subterrâneas e o índice PROX_AM na região de Dobrogea, Romênia. Segundo o autor, geralmente uma maior aglutinação de grandes manchas agrícolas potencializa os níveis de nitrato nas águas subterrâneas.

\section{CONCLUSÕES}

O emprego das métricas de paisagem e do geoprocessamento proporcionou a análise das mudanças do uso e cobertura do solo da APA do rio Uberaba sob o enfoque da ecologia de paisagens. De maneira geral, o período de 1994 a 2014 apresentou uma mudança negativa na configuração e composição da paisagem, fruto da expansão das atividades agropecuárias. Tal fato pode ser comprovado pela diminuição do número de manchas da classe Mata acompanhado pelo decréscimo de sua área total, chegando a $27,4 \%$ da área total da APA, abaixo do limiar mínimo de 30\% recomendado segundo a literatura.

Outros índices também mostram uma perda de qualidade e quantidade de habitats florestais na APA entre 1994 e 2014, como aumento do índice de forma médio, gerando manchas distorcidas com elevado efeito de borda, e a diminuição do índice de proximidade média ponderado pela área, evidenciando um aumento no distanciamento de fragmentos florestais maiores. Em meio a esse cenário, diversos processos ambientais e ecológicos podem ser afetados com essas alterações, tais como a dificuldade no fluxo de espécies entre as manchas florestais, o assoreamento dos cursos d'água causado pelo desmatamento interferindo na vida aquática, bem como a perda da qualidade da água para o abastecimento público.

Devido à importância dos serviços ambientais gerados pela APA do rio Uberaba, é preciso aumentar a compreensão da dinâmica da sua paisagem, bem como adotar medidas que contribuam de forma efetiva para seu manejo. Nesse sentido, a abordagem da Ecologia de Paisagem, através dos índices de paisagem, permitiu uma análise estrutural da paisagem da APA em microescala, sendo uma ferramenta auxiliar para a tomada de decisão de políticas públicas.

\section{REFERÊNCIAS}

ABDALA, V. L. "Zoneamento ambiental da bacia do alto curso do Rio Uberaba-MG como subsídio para gestão do recurso hídrico superficial". 2005. 87 f. Dissertação (Mestrado) - Curso de Geografia, Universidade Federal de Uberlândia, Uberlândia, 2005. 
BARBALHO, M. G. da S.. Avaliação temporal do perfil da vegetação da microrregião dCeres atre avés do uso de métricas de paisagem. Bol. Goia. Geogr., Goiânia, v. 35, n. 3, p.472-487, set./dez. 2015.

CABACINHA, C. D.. Análise da estrutura da paisagem da alta bacia do rio Araguaia na savana brasileira. Floresta, Curitiba, v. 40, n. 4, p.675-690, out./dez. 2010.

CÂNDIDO, H. G. et al. Degradação Ambiental da Bacia Hidrográfica do Rio Uberaba: Uma Abordagem Metodológica. Engenharia Agrícola, Jaboticabal, v. 30, n. 1, p.179-192, jan./fev. 2010.

FARINA, A. Principles and methods in landscape ecology: Toward a Science of Landscape. Urbino: Springer, 2006. 430 p.

FERNANDES, M. et al. Ecologia da Paisagem de uma Bacia Hidrográfica dos Tabuleiros Costeiros do Brasil. Floresta e Ambiente, [s.I.], v. 24, p.1-9, 2017.

GALETTI, G. Diagnóstico da estrutura da paisagem da estação ecológica de Avaré e seu entorno, como subsídio à sua conservação. 2013. 61 f. Dissertação (Mestrado) Curso de Ciências Ambientais, Universidade Federal de São Carlos, Sorocaba, 2013.

LOURENÇO, D. C. G. R. Avaliação de áreas invadidas por espécies de Acacia na Paisagem Protegida da Arriba Fóssil da Costa de Caparica. 2009. 89 f. Dissertação (Mestrado) - Curso de Engenharia do Ambiente, Universidade Nova de Lisboa, Lisboa, 2009.

LUCAS, D. F. Análise Espacial dos Fragmentos Florestais no Município de São Gonçalo do Rio Abaixo/MG. Monografia. XIII Curso de Especialização em Geoprocessamento. 2011.

MASSOLI JUNIOR, E. V.. Estimativa da fragmentação florestal na microbacia Sepotubinha, Nova Marilândia - MT, entre os anos de 1990 a 2014. Caminhos da Geografia, Uberlândia, v. 17, n. 60, p.48-60, dez. 2016.

MCGARIGAL, K.; MARKS, B. J. Fragstats: spatial pattern analysis program for quantifying landscape structure. Reference manual, version 2.0. Corvallis, Oregon: For. Sci. Dep. Oregon State University, 1994.

METZGER, J. P. Estrutura da Paisagem e Fragmentação: Análise Bibliográfica. Anais...Academia Brasileira de Ciências. v.71, n. 3-I, 445-463, Rio de Janeiro.1999.

METZGER, J. P. O Código Florestal tem base científica? Natureza e Conservação, São Paulo, v. 8, n. 1, p.1-8, jun. 2010.

OLIVEIRA FILHO, F. J. B. de; METZGER, J. P.. Thresholds in landscape structure for three common deforestation patterns in the Brazilian Amazon. Landscape Ecology, [s.I.], v. 21, n. 7, p.1061-1073, out. 2006. 
OLIVEIRA, J. S. de et al. Análise espacial como suporte ao planejamento ambiental da região do Quadrilátero Ferrífero, Minas Gerais. Geographia Meridionalis, [s.I.], v. 3, n. 1, p.134-156, jan./jun. 2017.

PARANHOS FILHO, A. C. Sensoriamento Remoto Ambiental Aplicado. Campo Grande: Ufms, 2008. 198 p.

PEREIRA, R. da S. et al. Expansão da cana-de-açúcar no município de Uberaba - MG. In: SIMPÓSIO INTERNACIONAL DE ÁGUAS, SOLOS E GEOTECNOLOGIAS - SASGEO, 1., 2015, Uberaba. Anais...Uberaba: Sasgeo, 2015.

PIROVANI, D. B.. Análise da paisagem e mudanças no uso da terra no entorno da rppn cafundó, ES. Cerne, [s.I.], v. 21, n. 1, p.27-35, mar. 2015.

RUDOLPHO, L. da S. et al. Aplicação de técnicas de geoprocessamento e métricas da paisagem na análise temporal da cobertura florestal da Bacia do Ribeirão Fortaleza em Blumenau/SC. In: SIMPÓSIO BRASILEIRO DE SENSORIAMENTO REMOTO, 16., 2013, Foz do Iguaçu. Anais... . Foz do Iguaçu: Inpe, 2013. p. 1742 - 1749.

RUSCA, G. G. et al. Análise espacial dos fragmentos florestais no entorno de uma unidade de conservação de proteção integral. Revista Brasileira de Ciências Ambientais (online), [s.l.], n. 44, p.85-94, jun. 2017.

SAUNDERS, Denis A. et al. Biological Consequences of Ecosystem Fragmentation: A Review. Conservation Biology, [s.i], v. 5, n. 1, p.18-32, mar. 1991.

SAURA, S.. EDITOR'S CHOICE: Stepping stones are crucial for species' long-distance dispersal and range expansion through habitat networks. Journal Of Applied Ecology, [s.I.], v. 51, n. 1, p.171-182, 13 nov. 2014.

SHAKER, R. et al. Land cover and Landscape as predictors Of groundwater contamination: a neural-network modelling approach applied to Dobrogea,

Romania. Journal Of Environmental Protection And Ecology, [s.I.], v. 11, n. 1, p.337348, mar. 2010.

TURNER, M. G. Landscape Ecology: What Is the State of the Science?. Annual Review of Ecology, Evolution and Systematics., [s.I.], v. 36, n. 1, p.319-344, ago. 2005.

UBERABA. Prefeitura Municipal de Uberaba. Plano de manejo emergencial: Área de proteção ambiental municipal do rio Uberaba. Uberaba, 2012. 136p. Disponível em:< http://www.uberaba.mg.gov.br/portal/acervo/meio_ambiente/APA/Plano\%20de\%20Manejo \%20Emergencial\%20-\%20APA\%20Rio\%20Uberaba\%20-\%202013.pdf> Acesso em: 15 nov. 2017.

UUEMAA, E. Trends in the use of landscape spatial metrics as landscape indicators: A review. Ecological Indicators, [s.I.], v. 28, p.100-106, maio 2013. 
VALENTE, R. de O. A. Análise da Estrutura da Paisagem na Bacia do Rio Corumbataí, SP. 2001. Dissertação (Mestrado em Recursos Florestais). Escola Superior de Agricultura "Luiz de Queiroz", Universidade de São Paulo, Piracicaba, 2001.

VALERA, C. A. et al. The Buffer Capacity of Riparian Vegetation to Control Water Quality in Anthropogenic Catchments from a Legally Protected Area: A Critical View over the Brazilian New Forest Code. Water, [s.I.], v. 11, n. 3, p.1-16, mar. 2019.

VALERA, C. A. et al. The role of environmental land use conflicts in soil fertility: A study on the Uberaba River basin, Brazil. Science Of The Total Environment, [s.I.], v. 562, p.463473, ago. 2016.

VALLE JUNIOR, R. F. do. Diagnóstico de áreas de risco de erosão e conflito de uso dos solos na bacia do rio Uberaba. 2008. $222 \mathrm{f}$. Tese (Doutorado) - Curso de Agronomia (produção Vegetal), Universidade Estadual Paulista, Jaboticabal, 2008.

VALLE JUNIOR, R. F. do et al. Potencial de erosão da bacia do rio Uberaba. Eng. Agríc., Jaboticabal, v. 30, n. 5, p.897-908, set./out. 2010.

VIDOLIN, G. P. Análise da estrutura da paisagem de um remanescente de floresta com Araucária, Paraná, Brasil. Revista Árvore, Viçosa, v. 35, n. 3, p.515-525, abr. 2011.

VOLOTÃO, C. F. de S. Trabalho de análise espacial Métricas do Fragstats. Instituto Nacional De Pesquisas Espaciais/INPE. São Jose dos Campos, 1998.

WEISS, Carlos Vinicius da Cruz et al. Análise comparativa entre métodos de correção atmosférica em imagens do sensor Operational Land Imager (OLI), plataforma Landsat 8. Scientia Plena, Rio Grande, v. 11, n. 2, p.1-8, fev. 2015.

Recebido em: 19/02/2019

Aprovado em: 06/05/2019 